\title{
Analisis finansial usaha rumpon pada kelompok tani nelayan Malos III Malalayang I Timur, Kota Manado
}

\author{
FADs business financial analysis on farmers and fishermen group Malos III in \\ East Malalayang I, Manado City \\ TONNY YEHESKEL NAPASAU, LEFRAND MANOPPO* dan EFFENDI P. SITANGGANG. \\ Program Studi Pemanfaatan Sumberdaya Perairan Fakultas Perikanan dan Ilmu Kelautan, \\ Universitas Sam Ratulangi Manado 95115
}

\begin{abstract}
Efforts to catch fish in large quantities require time and a large number of fishing gears as well as increasing fishing intensity. FADs is one method of fishing which aims to collect fish in a catchable area so that fishing can be done effectively and efficiently. This study aimed to analyze the FADs business run by Farmers and Fishermen Group Malos III in East Malalayang I, Manado City; to know the profit-sharing system and depositing dues or fees on group cash. This research was done with descriptive method which is based on case studies. The research results showed that investment cost is Rp.38.933.000; fixed cost is Rp. 19.999.500; variable cost is Rp. 142.250.000; and total cost is Rp. 162. 249.500. Average production value is Rp. 122.857.616; absolute profit is Rp. 177.720083. benefit cost ratio average is 7.59; break even point average is Rp. 3.769 .891 ; profitability average is $14.69 \%$ and average payback period is 0.07 years ( 1 month). Results of the analysis indicated that the business FADs on KTN Malos III in East Malalayang I Manado was very profitable. Revenue sharing system was $70 \%$ for the owner of fishing gear (small purse seine) and $30 \%$ for the owners of FADs on each fishing operations.
\end{abstract}

Keywords: FADs, KTN Malos III, break even point, revenue sharing system.

\begin{abstract}
ABSTRAK
Upaya menangkap ikan dalam jumlah besar memerlukan waktu dan jumlah alat tangkap yang lebih besar serta peningkatan intensitas pengoperasiannya. Rumpon merupakan salah satu metode dalam penangkapan ikan yang bertujuan untuk mengumpulkan ikan dalam satu area penangkapan agar penangkapan ikan dapat dilakukan secara efektif dan efisien. Penelitian ini bertujuan untuk menganalisis usaha rumpon dari Kelompok Tani Nelayan Malos III Malalayang I Timur, Kota Manado; untuk mengetahui system bagi hasil dan penyetoran iuran atau fee pada kas kelompok. Penelitian ini dikerjakan degan metode deskritif didasarkan pada studi kasus. Hasil penelitian menunjukkan bahwa biaya investasi sebesar Rp.38.933.000; biaya tetap Rp. 19.999.500; biaya tidak tetap Rp. 142.250.000; biaya total Rp. 162.249.500. Nilai produksi rata-rata Rp. 122.857.616; keuntungan absolut Rp. 177.720.083; benefit cost ratio rata-rata 7,59; break even point rata-rata Rp. 3.769.891; rentabilitas rata-rata14,69\% dan jangka waktu pengembalian rata-rata 0,07 tahun (1 bulan). Hasil analisis menyatakan usaha rumpon pada KTN Malos III Kelurahan Malalayang I Timur Manado sangat menguntungkan. Sistem bagi hasil yang berlaku adalah 70 $\%$ untuk pemilik alat tangkap (soma pajeko) dan $30 \%$ untuk pemilik rumpon pada setiap kali operasi penangkapan.
\end{abstract}

Kata-kata kunci: rumpon, KTN Malos III, break even point, sistem bagi hasil

\section{PENDAHULUAN}

Potensi perikanan laut terdiri dari dua jenis, yaitu jenis ikan pelagis dan jenis ikan demersal, sementara sumberdaya ikan pelagis dibagi lagi menjadi dua jenis, yaitu ikan pelagis kecil dan

\footnotetext{
${ }^{1}$ Penulis untuk penyuratan; email: tonnynapasau@yahoo.com
}

pelagis besar. Pada umumnya ikan pelagis memiliki tingkah laku yang suka bergerombol, sehingga dalam teknik penangkapannya harus disesuaikan dengan tingkah laku ikan target, karena keberhasilan operasi penangkapan ikan adalah merupakan suatu teknik atau metode bagaimana mengendalikan tingkah laku ikan agar 
terkonsentrasi pada suatu area tangkap (catchable area), sehingga mudah untuk ditangkap. Alat bantu yang biasanya digunakan untuk mengkonsentrasikan ikan pelagis kecil termasuk di perairan Teluk Manado adalah rumpon. Namun pada beberapa tahun terakhir ini, pemilik pajeko (pukat cincin) dan pemilik rumpon merupakan usaha individu atau kelompok yang terpisah. Berdasarkan penjelasan di atas, penulis ingin menelaah tentang usaha pengoperasian rumpon pada Kelompok Tani Nelayan Malos III, Malalayang I Timur, Manado.

Penelitian ini bertujuan untuk menganalisis usaha rumpon dari Kelompok Tani Nelayan Malos III Malalayang I Timur, Kota Manado dan mengetahui sistem bagi hasil antara pemilik alat tangkap pajeko dan rumpon serta penyetoran anggota pada kas kelompok atau fee pada satu trip penangkapan.

Hasil penelitian ini diharapkan dapat digunakan sebagai salah satu informasi penting bagi pemilik pajeko dan pemilik rumpon dalam memperbaiki atau meningkatkan jumlah hasil tangkapan ikan yang pada gilirannya akan dapat menunjukkan pendapatan yang lebih memuaskan kedua belah pihak.

Di samping itu, hasil penelitian ini diharapkan dapat digunakan oleh pemerintah sebagai salah satu landasan dalam pengambilan kebijakan dalam rangka memanfaatkan potensi perikanan laut, terutama petani sumberdaya ikan pelagis secara optimal, rasional dan berkelanjutan. Penelitian ini dilakukan di sekitar Teluk Manado (Malalayang I) pada Desember 2014 sampai Januari 2015, yang berkerjasama dengan Kelompok Tani Nelayan (Malos) III Malalayang I Timur, Kecamatan Malalayang, Kota Manado, Provinsi Sulawesi Utara.

\section{METODOLOGI PENELITIAN}

Penelitian bersifat deskritif didasarkan pada studi kasus, yang dilakukan dengan cara mempelajari suatu kasus secara intensif dan mendalam pada suatu subyek terbatas (Surahkmad, 1982). Adapun kasus yang menjadi obyek penelitian ini yaitu, usaha penangkapan ikan dengan alat bantu rumpon pada KTN Malos III Malalayang I Timur, Kota Manado, Provinsi Sulawesi Utara.

Data yang dikumpulkan berupa data primer dan data sekunder. Sedangkan untuk mengetahui kelayakan analisis ini dilakukan analisis finansial seperti: (a) Operating profit adalah keuntungan yang diperoleh dari penerimaan dikurang biaya tidak tetap; (b) Tingkat keuntungan absolut adalah keuntungan bersih yang diperoleh dari total penerimaan dikurang total biaya; (c) Benefit Cost Ratio (BCR) adalah total pendapatan dibagi dengan total pengeluaran yang dinyatakan dalam persen; (d) Rentabilitas adalah total pendapatan dibagi dengan total modal (investasi) yang usaha tersebut dan dinyatakan dalam persen; (e) Break Even Point (BEP) adalah suatu keadaan di mana usaha yang dilakukan tidak mengalami kerugian ataupun keuntungan, di mana jika BEP $<1$, usaha tersebut mengalami kerugian, jika BEP $=1$, usaha tersebut tidak untung dan tidak rugi, dan jika BEP $>1$, usaha tersebut menguntungkan; (f) Jika waktu pengembalian adalah kemampuan untuk mengembalikan modal yang digunakan dalam menjalankan usaha yang dihitung dari total modal usaha dibagi dengan keuntungan bersih dinyatakan dalam tahun.

Adapun data yang diperoleh akan dianalisis dengan pendekatan formula (Soetrisno, 1983) sebagai berikut:

Operating profit:

$$
\text { Pendapatan total - biaya total }
$$

Keuntungan absolut:

$$
\begin{aligned}
\pi & =\mathrm{Tr}-\mathrm{Tc} \\
& =\text { total penerimaan- total biaya }
\end{aligned}
$$

BCR: $\quad \frac{\operatorname{Tr}}{\mathrm{Tc}}=\frac{\text { Total pendapatan }}{\text { Total biaya }}$

Rentabilitas: $\frac{\pi}{\mathrm{I}} \frac{(\text { Total Pendapatan })}{(\text { Totalmodal })} \times 100 \%$

Jangka waktu pengembalian:

$$
\frac{\mathrm{I}(\text { Investasi) }}{\pi \text { (Keuntungan) }} \times 1 \text { tahun }
$$

BEP Penjualan:

Keterangan:

$$
\frac{\mathrm{FC}}{1-\left(\frac{V C}{T r}\right)}
$$

$$
\begin{aligned}
& \mathrm{Tr}=\text { Total penerimaan }(\text { total revenue) } \\
& \mathrm{Tc}=\text { Total biaya }(\text { total cost }) \\
& \pi=\text { Keuntungan }(\text { profit) } \\
& \mathrm{Fc}=\text { Biaya tetap } \text { (fixed cost) } \\
& \mathrm{Vc}=\text { Biaya tidak tetap } \text { (variabel cost }) \\
& \mathrm{I}=\text { Investasi }
\end{aligned}
$$




\section{HASIL DAN PEMBAHASAN}

\section{Sejarah KTN Malos, III Malalayang I Timur}

Kelompok Tani Nalayan (KTN) Malos III dibentuk pada tahun 2010. KTN ini beranggotakan 45 orang nelayan; yang memiliki 7 unit rumpon, yang pada saat itu kelompok diketuai adalah Bapak Carter Sumayow. Anggota kelompok ini memiliki perahu, dan alat tangkap pancing dan jaring landra yang dioperasikan di belakang pajeko (pukat cincin). Dengan berjalannya waktu, maka jumlah rumpon yang dimiliki saat ini sebanyak 6 unit.

\section{Analisis finansial usaha}

Modal usaha yang diinvestasikan dalam menjalankan usaha rumpon dalam KTN Malos III sebesar Rp. 13.933.000,- per unit (Tabel 1). investasi tersebut berasal dari swadaya anggota kelompok dan bantuan dari pemerintah (KUB), penilaian ini berdasarkan keriteria di bawah ini.

\section{Biaya investasi}

Biaya investasi adalah biaya yang dikeluarkan satu kali dalam satu periode proses produksi untuk memperoleh berapa kali manfaat secara ekonomis yang dikeluarkan pada awal kegiatan. Modal investasi yang dibutuhkan pada KTN Malos III adalah 1 unit motor tempel Yamaha $15 \mathrm{pk}$, dan 1 unit pada setiap unit rumpon. Berdasarkan jumlah biaya investasi yang dibutuhkan, untuk pembuatan 6 unit rumpon oleh KTN Malos III Malalayang I Timur tercatat rata-rata Rp.13.933.000,-.

\section{Biaya tetap}

Biaya tetap adalah biaya yang digunakan dalam menjalankan usaha rumpon KTN hingga mencapai target usia ekonomi suatu usaha, meliputi biaya pembuatan unit rumpon, biaya perawatan, dan biaya penyusutan, dengan kisaran harga yang relatif sama antara rumpon 1-6 pada Tabel 2.

Tabel 1. Biaya tetap KTN, Malos III.

\begin{tabular}{|c|c|c|c|c|}
\hline \multicolumn{5}{|c|}{ Biaya Tetap(Rp/thn) } \\
\hline \multicolumn{3}{|c|}{ Penyusutan } & \multirow[b]{2}{*}{ Perawatan (Rp) } & \multirow[b]{2}{*}{$\begin{array}{c}\text { Jumlah } \\
\text { (Rp) }\end{array}$} \\
\hline Rumpon & Motor (Rp) & Rumpon (Rp) & & \\
\hline R. 1 & 1.000 .000 & 2.233 .250 & 100.000 & 3.333 .250 \\
\hline R. 2 & 1.000 .000 & 2.233 .250 & 100.000 & 3.333 .250 \\
\hline R. 3 & 1.000 .000 & 2.233 .250 & 100.000 & 3.333 .250 \\
\hline R. 4 & 1.000 .000 & 2.233 .250 & 100.000 & 3.333 .250 \\
\hline R. 5 & 1.000 .000 & 2.233 .250 & 100.000 & 3.333 .250 \\
\hline R. 6 & 1.000 .000 & 2.233 .250 & 100.000 & 3.333 .250 \\
\hline Jumlah (Rp) & 6.000 .000 & 13.399 .500 & 600.000 & 19.999 .500 \\
\hline
\end{tabular}

Berdasarkan Tabel 1 dapat dilihat jumlah biaya tetap yang dibutuhkan, untuk pembuatan 6 unit rumpon oleh KTN Malos III, tercatat biaya tetap sebesar Rp. 19.999.500 per tahun atau rata-rata senilai Rp.3.333.250 per tahun.

\section{Biaya tidak tetap}

Dalam menjalankan kegiatan usaha memerlukan biaya untuk menunjang kegiatan usaha rumpon tersebut, di antaranya: Biaya pembelian BBM dan oli, makan, rokok, dan pulsa. Biaya-biaya ini digunakan untuk menunjang kebutuhankegiatan operasi penangkapan ikan oleh usaha alat bantu penangkapan ikan (rumpon).

Dengan jumlah Rp142.250.000 atau nilai ratarata per satu unit rumpon sebesar Rp. 28.450 .000 per tahun. Berdasarkan data yang diperoleh dari ketua KTN Malos III.

Tabel 2. Biaya tidak tetap (BO)

\begin{tabular}{lll}
\hline Rumpon & $(\mathrm{Rp} / \mathrm{b} \ln )$ & $10 \mathrm{bln} / \mathrm{thn}$ \\
\hline R1 & 2.175 .000 & 21.750 .000 \\
R2 & 2.150 .000 & 21.500 .000 \\
R3 & 2.275 .000 & 22.750 .000 \\
R4 & 2.225 .000 & 22.250 .000 \\
R5 & 2.700 .000 & 27.000 .000 \\
R6 & 2.700 .000 & 27.000 .000 \\
\hline Jumlah (Rp) & 14.225 .000 & 142.250 .000 \\
\hline Rata - rata & 2.370 .833 & 28.450 .000 \\
\hline
\end{tabular}


Pada Tabel 3 terlihat bahwa jumlah biaya tidak tetap pada ke dua lokasi penempatan rumpon sehingga mengakibatkan pada pengunaan bahan bakar yang berimplikasi pada biaya operasi penangkapan trip per hari pada setiap unit rumpon, biaya tidak tetap pada ke enam unit rumpon.

Tabel 3. Rincian jenis (BO) trip/hari KTN Malos III

\begin{tabular}{lcc}
\hline \multirow{2}{*}{ Jenis Biaya Operasi (BO) } & \multicolumn{2}{c}{ Biaya Operasi (Rp./Hari) } \\
\cline { 2 - 3 } & Lokasi I (Rp) & Lokasi II (Rp) \\
\hline BBM dan Oli & 38.000 & 63.000 \\
Konsumsi & 10.000 & 10.000 \\
Keperluan lain & 27.000 & 27.000 \\
\hline Jumlah & 75.000 & 100.000 \\
\hline Sumber : KTN Malos III Malalayang I Timur, (2013)
\end{tabular}

Tabel 4. Biaya total Februari-Maret 2013, pada 6 unit rumpon KTN, Malos III.

\begin{tabular}{cccc}
\hline Rumpon & Biaya tetap $(\mathrm{Rp})$ & Biaya tidak tetap $(\mathrm{Rp})$ & Biaya total $(\mathrm{Rp})$ \\
\hline R1 & 3.333 .250 & 21.750 .000 & 25.083 .250 \\
R2 & 3.333 .250 & 21.500 .000 & 24.833 .250 \\
R3 & 3.333 .250 & 22.750 .000 & 26.083 .250 \\
R4 & 3.333 .250 & 22.250 .000 & 25.583 .250 \\
R5 & 3.333 .250 & 27.000 .000 & 30.333 .250 \\
R6 & 3.333 .250 & 27.000 .000 & 30.333 .250 \\
\hline Jumlah $(\mathrm{Rp})$ & 19.999 .500 & 142.250 .000 & 162.249 .500 \\
\hline
\end{tabular}

\section{Pendapatan dan nilai produksi}

Ikan hasil pembagian ada yang di jual langsung ke pasar, maupun ke pedagang penggumpul yang ada di wilayah tersebut. Sedangkan ikan yang di jual di pasar secara langsung oleh para istri dari masingmasing anggota KTN. Jenis ikan yang di pasarkan yaitu tude (Selaroides sp.), deho (Auxisrochii), malalugis (Decapterus sp), harga jual ikan hasil tangkapan berkisar antara Rp. $12.000-16.000$ per $\mathrm{kg}$.

Jika diasumsikan pengoperasian rumpon dalam satu tahun dilakukan rata-rata 10 bulan, maka pendapatan yang diperoleh dalam waktu satu bulan sebesar Rp. 18.417.000 dan dalam setahun Rp. 184.170.000. rencian nilai produksi dan pendapatan masing-masing rumpon disajikan dalam Tabel 5 dan hasil analisis financial Tabel 6 .

Tabel 5. Nilai produksi dan pendapatan KTN, Malos III.

\begin{tabular}{cccc}
\hline \multirow{2}{*}{ Rumpon } & \multicolumn{3}{c}{ Nilai Produksi dan Pendapatan Kotor } \\
\cline { 2 - 4 } & Hasil/bln(kg) & $(\mathrm{Rp}) / \mathrm{bln}$ & $(\mathrm{Rp}) 10 \mathrm{bln} / \mathrm{thn}$ \\
\hline R1 & 1.315 .5 & 18.417 .000 & 184.170 .000 \\
R2 & 1.486 .5 & 20.811 .000 & 208.110 .000 \\
R3 & 1.379 .5 & 19.313 .000 & 193.130 .000 \\
R4 & 1.393 .5 & 19.509 .000 & 195.090 .000 \\
R5 & 1.538 .5 & 21.539 .000 & 215.390 .000 \\
R6 & 1.662 .0 & 23.268 .000 & 232.680 .000 \\
\hline Rata-rata & 14.625 .833 & 2.047 .616 .667 & 122.857 .616$. \\
\hline
\end{tabular}


Tabel 6. Hasil analisa finansial usaha rumpon KTN Malos III

\begin{tabular}{ccccccc}
\hline Rumpon & $\begin{array}{c}\text { Pendapatan/ } \\
\text { thn (Rp.) }\end{array}$ & $\begin{array}{c}\text { Keuntungan } \\
\text { absolute (Rp.) }\end{array}$ & BCR & BEP & Rentabilitas & $\begin{array}{c}\text { Waktu } \\
\text { pengembalian }\end{array}$ \\
\hline 1 & 184.170 .000 & 159.086 .750 & 7,34 & 3.779 .612 & $1,321,825,881$ & 0,08 \\
2 & 208.110 .000 & 183.276 .750 & 8,38 & 3.717 .286 & $1,493,648,173$ & 0,07 \\
3 & 193.130 .000 & 167.046 .750 & 7,40 & 3.778 .322 & $138,613,364$ & 0,08 \\
4 & 195.090 .000 & 169.506 .750 & 7,63 & 3.762 .345 & $1,400,200,962$ & 0,08 \\
5 & 215.390 .000 & 185.056 .750 & 7,10 & 3.810 .970 & $1,545,898,227$ & 0,07 \\
6 & 232.680 .000 & 202.346 .750 & 7,67 & 3.770 .812 & $1,669,992,105$ & 0,06 \\
\hline Rata-rata & 122.857 .616$. & 177.720 .083 & 7,59 & 3.769 .891 & $1,469,616,498$ & 0,07 \\
\hline
\end{tabular}

Analisis Benefit Cost Ratio adalah analisa dari enam rumpon diperoleh nilai $\mathrm{BC}$ ratio berkisar antara 7,34-8,38 dengan nilai BCR rata-rata sebesar 7,59 dengan (Tabel 6). Dari Tabel 7 dapat dilihat bahwa BCR dari setiap rumpon memperoleh keuntungan karena nilai $\mathrm{BC}$ ratio lebih besar dari satu. Jadi rumpon 1, 3, 4, 5 dan 6 memperoleh keuntungan sebanyak 6 kali lipat, sedangkan rumpon 2 sebanyak 7 kali lipat.

Break Even Point adalah titik impas, jika pendapatan sama besar dengan BEP berarti impas usaha tersebut tidak menguntungkan atau tidak merugi, tapi jika nilai pendapatan lebih besar dari BEP berarti perusahan memperoleh keuntungan.

Dari hasil analisis usaha pada masing-masing unit rumpon diperoleh nilai sebesar 3,7-3,8 (Tabel 6) hal ini menunjukkan bahwa usaha rumpon yang dilakukan oleh KTN memiliki keuntungan yang relatif tinggi, hal ini sejalan dengan teori ekonomi jika BEP lebih besar satu maka usaha menguntungkan. Dengan kata lain usaha rumpon yang dilakukan oleh KTN sangat menguntungkan bagi kelompok maupun anggota kelompok. Keuntungan yang diperoleh setiap unit usaha sebesar Rp. 3 juta.

Rentabilitas merupakan kemampuan seorang pengusaha menghasilkan keuntungan dibandingkan dengan modal yang digunakan dan dinyatakan dengan persen. Berdasarkan hasil analisis menunjukkan bahwa rata-rata rentabilitas usaha rumpon sebesar 14,69\% (Tabel 6), rincian rentabilitas dan jangka waktu pengembalian ratarata sebesar 0,07 (thn) untuk ke enam unit rumpon disajikan dalam Tabel 7 menunjukkan bahwa rentabilitas dari rumpon 1 dan rumpon 3 sebesar $13 \%$, rumpon 2 dan rumpon 4 sebesar $14 \%$, rumpon 5 dan rumpon 6 masing-masing sebesar 15 dan $16 \%$. Dengan kata lain dalam satu tahun nelayan dapat membeli kembali rumpon sebanyak rentabilitas yang diperoleh dari masing-masing rumpon.
Jangka waktu pengembalian adalah kemampuan untuk mengembalikan modal yang digunakan dalam menjalankan usaha yang dihitung dari total modal usaha dibagi dengan keuntungan bersih $n$ tahun atau diperoleh dari investasi dibagi keuntungan sehingga diperoleh jangka waktu pengembalian,untuk rumpon satu, rumpon dua rumpon tiga, rumpon empat dan rumpon lima yaitu 1 bulan jangka waktu pengembalian, untuk rumpon enam jangka waktu pengembalian 2 mingguatau $1 / 2$ bulan.

Keuntungan absolut adalah besarnya keuntungan yang dapat diperoleh nelayan setelah dikurangi dari biaya-biaya yang dikeluarkan (total biaya) disajikan dalam Tabel 7.

Tabel 7. Keuntungan absolut

\begin{tabular}{cc}
\hline Rumpon & Keuntungan absolut(Rp) \\
\hline R1 & 159.086 .750 \\
R2 & 183.276 .750 \\
R3 & 167.046 .750 \\
R4 & 169.506 .750 \\
R5 & 185.056 .750 \\
R6 & 202.346 .750 \\
\hline Rata-rata (Rp) & 177.720 .083 \\
\hline
\end{tabular}

Tabel 7 menujukkan bahwa keuntungan absolut setiap rumpon berkisar antara Rp.159.086.750, Rp.202.346.750, dengan rata-rata keutungan absolut sebesar Rp. 177.720.083,-. Hal ini menunjukkan bahwa besarnya keuntungan yang dapat diperoleh nelayan setelah total penerimaan dikurangi dengan biaya total pengeluaran.

\section{Sistim bagi hasil}

Sistim bagi hasil yang telah lama berlaku di Teluk Manado antara pemilik pajeko dan pemilik rumpon, yaitu $70 \%$ untuk pemilik pajeko dan 30\% untuk pemilik rumpondari hasil tangkapan persatu 
unit rumpon. Sistem bagi hasil yang ada bukan berupa uang, melainkan berupa pembagian hasil tangkapan. Sedangkan untuk anggota kelompok yang menjaga rumpon atau melakukan operasi penangkapan harus memberikan fee kepada kelompok sebesar 2\%. Sebagai contoh, Jika hasil tangkapan ikan pelagis yang diperoleh sebanyak $100 \mathrm{~kg}$, maka untuk pemilik pajeko mendapat 70 $\mathrm{kg}$ (Rp.980.000) dan untuk pemilik rumpon $30 \mathrm{~kg}$ (Rp. 420.000) dan fee dari pemilik rumpon untuk Kelompok 1,5 kg (Rp. 21.000).

\section{KESIMPULAN}

Berdasarkan tujuan penelitian, maka diperoleh hasil dan pembahasan yang dapat di simpulkan sebagai berikut:

Hasil analisis menyatakan usaha rumpon pada Kelompok Tani Nelayan Malos III Kelurahan Malalayang I Timur, Manado sangat menguntungkan. Sistem bagi hasil antar pemilik alat dan pemilik rumpon. $70 \%$ untuk pemilik alat dan untuk pemilik rumpon $30 \%$ pada satu kali operasi penangkapan.

\section{DAFTAR PUSTAKA}

Anonimus.1997 Standard statistik perikanan. Buku I. Direktorat Jenderal Perikanan, Departemen Pertanian, Jakarta.

Arikunto, S. 1986. Manajemen Penelitian. P2LPK.Jakarta

Suharsimi. 2008. Dasar-Dasar Evaluasi Pendidikan. Bumi Aksara, Yogyakarta.

Gunarso, W. 1985. Tingkah laku ikan dalam hubungannya dengan alat tangkap, metode dan taktik penangkapan. Diktat. Jurusan Pemanfaatan Sumberdaya Perikanan, Fakultas Perikanan, Institut Pertanian Bogor, Bogor.
Hella, I. dan T. Laevastu. 1981. Fisheries Oceanography and Ecology. Fishing News Book Ltd., London.

Katiandagho, E.M. 1994. Pengantar ilmu perikanan. Laboratorium Teknologi Penangkapann Ikan Fakultas Perikanan UNSRAT, Manado.

Monintja, D.R., B.P Pasaribu, dan I. Jaya. 1986. Manajemen penangkapan ikan. Fakultas Perikanan. IPB, Bogor.

Monintja, D.R. dan Zulkarnain. 1995. Analisis dampak pengoperasian rumpon tipe Phillipine di perairan ZEE terhadap perikanan cakalang di perairan teritorial selatan Jawa dan utara Sulawesi. Laporan Penelitian. Fakultas Perikanan, Institut Pertanian Bogor, Bogor.

Subani, W. 1986. Telaah penggunaan rumpon dan payaos dalam perikanan Indonesia. Jurnal Penelitian Perikanan Laut 35: 35-45.

Subani, W. dan H.R. Barus. 1989. Alat penangkapan ikan dan udang laut di Indonesia. Jurnal Penelitian Perikanan Laut 50.

Soetrisno. 1983. Dasar-Dasar Evaluasi Proyek Jilid I. Fakultas Ekonomi, UGM, Yogyakarta.

Surakhman,1982. Metodologi Penelitian Masyarakat. Penerbit LP3ES, Jakarta.

Sondita. M.F.A. 1986. Studi tentang peranan pemikatan ikan dalam operasi purse.milik PT. Tirta Raya Mina (Persero), Pekalongan. Skripsi. Fakultas Perikanan. Institut Pertanian Bogor, Bogor.

Takayama, S. 1959. Fishing with light in Japan. Bangkok : IPFC. Proch. 6th Sess, Tokyo, Japan. Sect. II and III IPFC Secr., FAO.

Tim Pengkajian Rumpon Fakultas Perikanan Institut Pertanian Bogor. 1987. Laporan akhir survai lokasi dan desain rumpon di perairan Ternate, Tidore, Bacan, dan sekitarnya. Laporan. Jurusan Pemanfaatan Sumberdaya Perikanan. Fakultas Perikanan dan Ilmu Kelautan, Institut Pertanian Bogor, Bogor.

Yusfiandayani, R. 2003. Studi mekanisme berkumpulnya ikan pelagis kecil di sekitar.rumpon dan model pengembangan perikanannya. Disertasi. Sekolah Pascasarjana, Institut Pertanian Bogor, Bogor.

Zulkarnain. 2002. Studi penggunaan rumpon pada bagan apung di Teluk Pelabuhanratu, Jawa Warat. Thesis. Program Pascasarjana. 